\title{
Diagnostic Performance of a Combination of Shear Wave Elastography and B-Mode Ultrasonography in Differentiating Benign From Malignant Thyroid Nodules
}

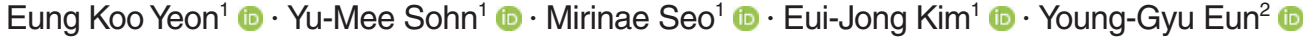 \\ Won Seo Park ${ }^{3}$ (i) $\cdot$ Seong Jong Yun ${ }^{4}$ [D \\ Departments of ${ }^{1}$ Radiology, ${ }^{2}$ Otolaryngology-Head and Neck Surgery, and ${ }^{3}$ Surgery, Kyung Hee University Hospital, Kyung Hee University \\ College of Medicine, Seoul; ${ }^{4}$ Department of Radiology, G SAM Hospital, Gunpo, Korea
}

Objectives. This study was conducted to compare clinicopathologic and radiologic factors between benign and malignant thyroid nodules and to evaluate the diagnostic performance of shear wave elastography (SWE) combined with Bmode ultrasonography (US) in differentiating malignant from benign thyroid nodules.

Methods. This retrospective study included 92 consecutive patients with 95 thyroid nodules examined on B-mode US and SWE before US-guided fine-needle aspiration biopsy or surgical excision. B-mode US findings (composition, echogenicity, margin, shape, and calcification) and SWE elasticity parameters (maximum [ $\left.\mathrm{E}_{\max }\right]$, mean, minimum, and nodule-to-normal parenchymal ratio of elasticity) were reviewed and compared between benign and malignant thyroid nodules. The diagnostic performance of B-mode US and SWE for predicting malignant thyroid nodules was analyzed. The optimal cutoff values of elasticity parameters for identifying malignancy were determined. Diagnostic performance was compared between B-mode US only, SWE only, and the combination of B-mode US with SWE.

Results. On multivariate logistic regression analysis, age (odds ratio [OR], 0.90; $P=0.028$ ), a taller-than-wide shape (OR, 11.3; $P=0.040)$, the presence of calcifications $(\mathrm{OR}, 15.0 ; P=0.021)$, and $\mathrm{E}_{\max }(\mathrm{OR}, 1.22 ; P=0.021)$ were independent predictors of malignancy in thyroid nodules. The combined use of B-mode US findings and SWE yielded improvements in sensitivity, the positive predictive value, the negative predictive value, and accuracy compared with the use of B-mode US findings only, but with no statistical significance.

Conclusion. When SWE was combined with B-mode US, the diagnostic performance was better than when only B-mode US was used, although the difference was not statistically significant.

Keywords. Shear Wave Elastography; Diagnostic Performance; Clinicopathologic and Radiologic Factors; Thyroid; Ultrasound

\footnotetext{
- Received August 6, 2019

Revised October 23, 2019

Accepted October 28, 2019

- Corresponding author: Yu-Mee Sohn

Department of Radiology, Kyung Hee University Hospital, Kyung Hee

University College of Medicine, 23 Kyungheedae-ro, Dongdaemun-gu,

Seoul 02447, Korea

Tel: +82-2-958-8625, Fax: +82-2-960-0787

E-mail: sonyumee@naver.com
}

\section{INTRODUCTION}

Ultrasonography (US) is the first-line and most preferred examination method for thyroid nodules. Conventional US can be used to detect nodules, and it also provides information on the composition, size, and number of nodules, as well as their anatomical relationships with surrounding structures. US findings that have been reported to be suggestive of malignant thyroid nodules include solid composition, hypoechogenicity or marked hypoechogenicity, a microlobulated or irregular margin, mixed

Copyright $\odot 2020$ by Korean Society of Otorhinolaryngology-Head and Neck Surgery

This is an open-access article distributed under the terms of the Creative Commons Attribution Non-Commercial License (https://creativecommons.org/licenses/by-nc/4.0)

which permits unrestricted non-commercial use, distribution, and reproduction in any medium, provided the original work is properly cited. 
calcification or microcalcifications, and a taller-than-wide shape $[1,2]$. However, a considerable number of US findings overlap between benign and malignant thyroid nodules, making it difficult to identify thyroid malignancies based on US imaging alone $[3,4]$. Fine-needle aspiration (FNA) can play an important role in differentiating thyroid nodules because it has a high sensitivity and specificity. However, the diagnostic performance of FNA depends on the operator's experience, it is an invasive method, and it yields a high proportion of indeterminate $(10 \%-20 \%)$ or nondiagnostic $(10 \%-15 \%)$ results $[5,6]$. The recently published World Federation for Ultrasound in Medicine and Biology guideline recommends US elastography as an additional modality in thyroid nodules to support surgical excision and periodic observation [7]. US elastography is a new sonographic imaging technology that estimates tissue hardness and helps to discriminate benign from malignant nodules. The basic concept of US elastography was first developed in 1991 by Ophir et al. [8]. Most malignant nodules have abnormally firm stroma because of the presence of myofibroblasts, which make it possible to differentiate thyroid cancer from benign nodules using elastography. Nell et al. [9] conducted a systematic review and meta-analysis of 20 studies. Their analysis demonstrated that unnecessary invasive diagnostic procedures such as FNA could be avoided in completely soft (Asteria elastography 1) thyroid nodules [10] with a $99 \%$ negative predictive value.

There are two kinds of US elastography: strain elastography and shear wave elastography (SWE) [11]. The limitations of strain elastography include difficulties with the quantitative estimation of tissue hardness and its low reliability as a result of operator dependency. In contrast, SWE uses transversely oriented shear waves created by mechanical vibration forces. The shear waves propagate faster in stiff tissue than in soft tissue, thus enabling a quantitative approach using color maps and elasticity indices including $\mathrm{E}_{\max }, \mathrm{E}_{\text {mean }}, \mathrm{E}_{\min }$, and $\mathrm{E}_{\text {ratio }}$ (with units of kilopascals [kPa]) [11]. This new technique has made it possible to evaluate tissue stiffness in a manner that is more quantitative, more reproducible, and less operator-dependent $[12,13]$. Some comparative studies found that SWE had lower interobserver variability than strain elastography; thus, it was preferred to real-time elastography and regarded as a promising tool with higher diagnostic performance and the ability to provide quantitative results for differentiating thyroid nodules [14].

\section{H I G G H L L I}

- Age, a taller-than-wide shape, the presence of calcifications, and $\mathrm{E}_{\max }$ were independent predictors of thyroid malignancy.

- The combination of B-mode ultrasonography with shear wave elastography (SWE) yielded improved diagnostic performance.

- SWE is a valuable additional diagnostic tool for predicting malignancy in thyroid nodules.
Until now, the majority of US elastography studies for predicting thyroid malignancies have investigated strain elastography [15-17]. To the best of our knowledge, only a few studies have investigated the use of SWE to identify thyroid malignancies, and those studies showed varying results in terms of diagnostic performance and the optimal cutoff values of elasticity parameters [18-21]. Therefore, the aim of this study was to compare clinicopathologic and radiologic factors between benign and malignant thyroid nodules and to evaluate and verify the diagnostic performance of a combination of SWE and B-mode US in distinguishing histologically proven malignant from benign thyroid nodules.

\section{MATERIALS AND METHODS}

\section{Patients}

This retrospective study of thyroid nodule analysis had institutional review board approval, and the need to obtain patient informed consent for the study was waived. From March 2016 to July 2017, 224 neck lesions from 214 consecutive patients underwent neck sonography using B-mode US and SWE before US-guided FNA (US-FNA) biopsy or surgical removal. Exclusion criteria were as follows: (1) non-thyroid lesion such as parotid gland, cervical lymph node (113 lesions in 106 patients), (2) unavailable for SWE imaging or elasticity parameters (one lesion in one patient) and (3) cytological results of non-diagnostic lesion or atypia of undetermined significance without surgical confirmation (15 lesions in 15 patients). Finally, 95 thyroid lesions in 92 patients were included in this study and finally diagnosed as benign and malignant by cytopathological confirmation as reference standard (US-FNA, $n=55$; surgical excision, $\mathrm{n}=40$ ). Patients consisted of 23 men and 69 women with a mean age of 52.12 years (range, 22 to 82 years). Fifty-four were benign thyroid nodules and 41 thyroid nodules were malignant.

\section{US examination}

All US examination including B-mode US and SWE scans were conducted with a 4-15 MHz linear transducer and a real-time US system (Aixplorer, SuperSonic Imagine, Aix en Provence, France) by two radiologists (YMS and MS) blinded to the result of histopathology with 7-11 years of experience in thyroid US and 6 years of elastography experience. Patients lied on the bed in a supine position with neck extension, the thyroid nodules and the neck were scanned carefully.

Each thyroid lesion was characterized according to B-mode US findings: composition (solid, mixed), echogenicity (marked hypoechoic, hypoechoic, isoechoic, mixed echoic), margin (irregular or microlobulated, circumscribed), calcifications (presence, absence) and shape (taller-than-wide, wider-than-taller). B-mode US characteristics for suspicious malignant findings were as follows; solid, marked hypoechogenicity or hypoechogenicity, ir- 
regular margin, presence of calcification, or taller-than-wide shape. The American Thyroid Association (ATA)'s guidelines for the management of thyroid nodule suggested five categories based on sonographic patterns [22]. (1) Nodules with the high suspicion of malignancy pattern, including solid hypoechoic nodule or solid hypoechoic component of a partially cystic nodule with one or more of the following US features: irregular margin, microcalcification, taller-than-wide shape, rim calcifications with small extrusive soft tissue component and evidence of extrathyroidal extension (Fig. 1). (2) Nodules with the intermediate suspicion of malignancy pattern, including hypoechoic solid nodule with smooth margins without microcalcifications, extrathyroidal extension, or taller than wide shape (Fig. 2). (3) Nodules with the low suspicion of malignancy pattern, including hyperechoic or isoechoic solid nodule, or partially cystic nodule with eccentric solid areas, without microcalcification, irregular margin or extrathyroidal extension, or taller than wide shape (Fig. 3). (4) Nodules with the very low suspicion pattern include spongiform or partially cystic nodules without any of the US features described in low, intermediate, or high suspicion patterns. (5) Benign pattern includes purely cystic nodules (no solid component). We used this ATA's guidelines, however, very low suspicion and benign patterns were not included in this study because these nodules were not referred to US-FNA.

SWE imaging was obtained on longitudinal sections in free- hand technique. The probe was placed gently in the patient's neck without external compression. The region of interest (ROI) (Q-box; SuperSonic Imagine) of the system was placed in the thyroid lesion with surrounding normal tissue, which showed translucent colored area of tissue hardness overlaid B-mode image with a range from blue to red. The lowest hardness was presented blue and the highest hardness was presented red (0-180 $\mathrm{kPa}$ ). Fixed $2 \times 2-\mathrm{mm}$ ROIs were located over the hardest part of the lesion with optimal image showing color homogeneity on the screen. Secondary same sized ROI was located in the normal thyroid tissue. The SWE system analyzed elasticity parameters of $E_{\text {mean }}$ (mean value of the ROI located in the hardest region), $\mathrm{E}_{\max }$ (maximum value of the ROI located in the hardest region), and $\mathrm{E}_{\min }$ (minimum value of the ROI located in the hardest region), and the $\mathrm{E}_{\text {ratio }}$ (ratio of mean stiffness for the lesion-to-normal parenchyma) was calculated automatically.

\section{Statistical analysis}

To evaluate the difference between benign and malignant nodule, either the independent $t$-test or Mann-Whitney $U$-test was used for the continuous variables and Pearson's chi-square test or Fisher's exact test was performed for the nominal variables. To assess the independent factor for discriminating thyroid malignancy from benign thyroid nodule, the multivariate logistic regression analysis was applied. Adjusted odds ratios (ORs) and

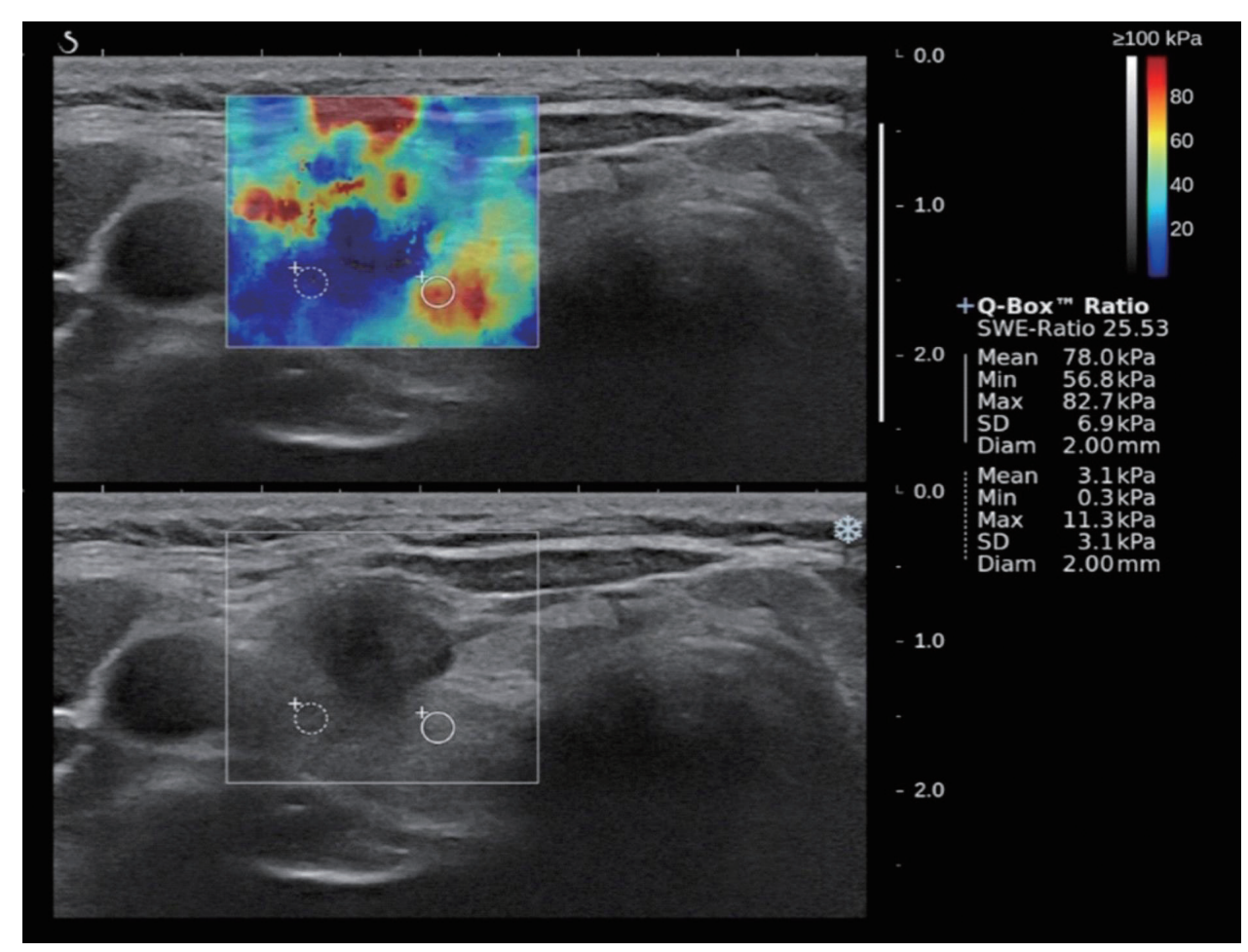

Fig. 1. A 53-year-old woman with surgically proven papillary thyroid carcinoma. B-mode ultrasound showed hypoechoic mass with irregular margin and microcalcifications which was assessed as a high suspicion. Shear wave elastography (SWE) displayed heterogenous color elasticity signal with peripheral high SWE (red). Measured elasticity parameters of $E_{\text {mean }}$ of $78.0 \mathrm{kPa}, E_{\max }$ of $82.7 \mathrm{kPa}$ and $\mathrm{E}_{\min }$ of $56.8 \mathrm{kPa}$ were obtained. 


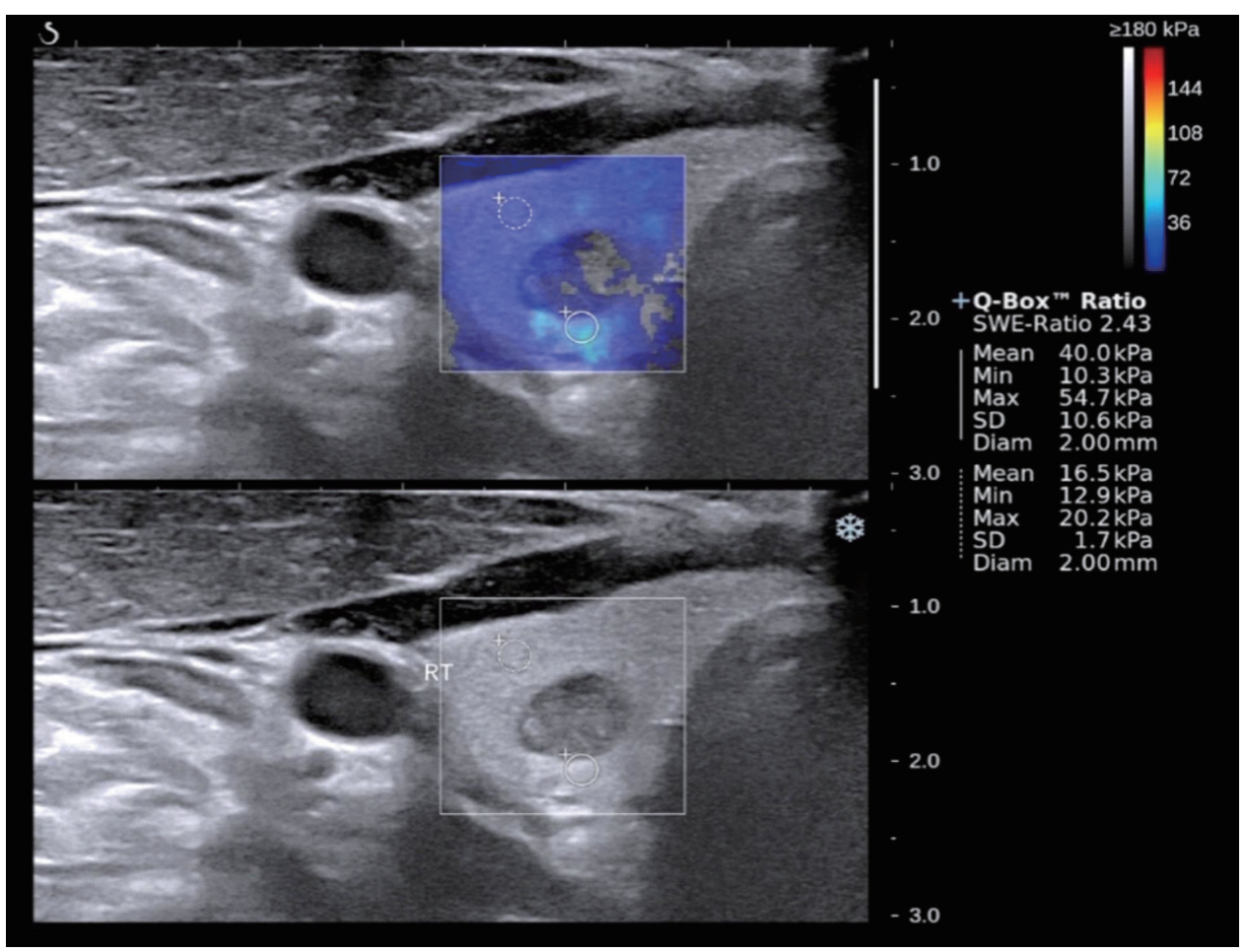

Fig. 2. A 36-year-old man with surgically proven papillary thyroid carcinoma. B-mode ultrasound showed mixed echoic mass with well-defined margin and oval shape which was assessed as an intermediate suspicion. Shear wave elastography (SWE) displayed relatively heterogenous color elasticity signal. Measured elasticity parameters of $E_{\text {mean }}$ of $40.0 \mathrm{kPa}, E_{\max }$ of $54.7 \mathrm{kPa}$ and $\mathrm{E}_{\min }$ of $10.3 \mathrm{kPa}$ were obtained.

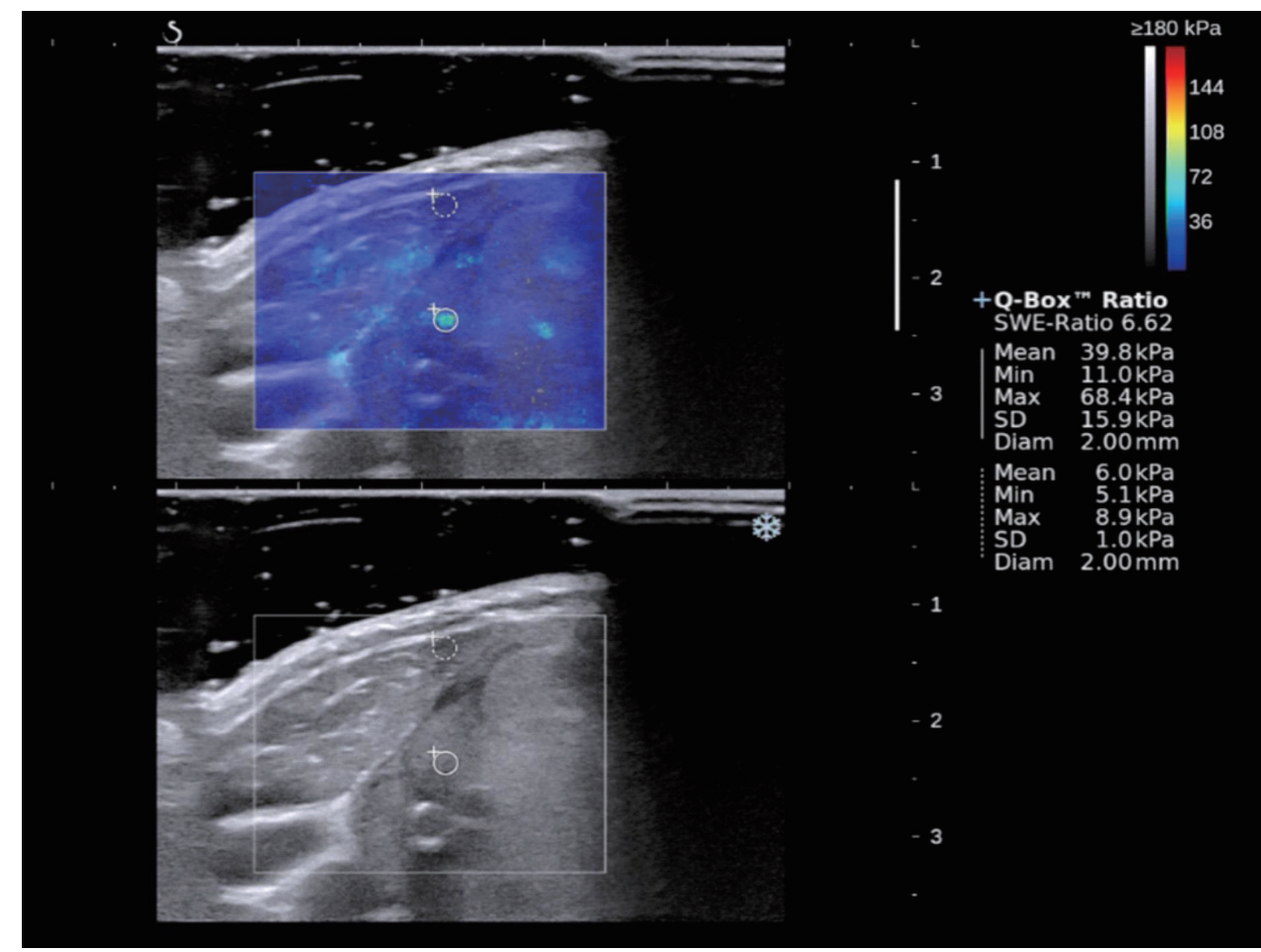

Fig. 3. A 57-year-old woman with surgically proven nodular hyperplasia. B-mode ultrasound showed isoechoic mass with well-defined margin and oval shape which was assessed as a low suspicion. Shear wave elastography (SWE) displayed relatively homogenous color elasticity signal. Measured elasticity parameters of $\mathrm{E}_{\text {mean }}$ of $39.8 \mathrm{kPa}, \mathrm{E}_{\max }$ of $68.4 \mathrm{kPa}$ and $\mathrm{E}_{\min }$ of $11.0 \mathrm{kPa}$ were obtained. 
95\% confidence intervals (CIs) were generated from the multivariate analyses.

To generate diagnostic performance and the cutoff values of the B-mode US and elastographic parameters for differentiation malignant thyroid nodule from benign nodule, a receiver operating characteristic (ROC) curve analysis was performed and areas under the ROC curves (AUCs) were analyzed. Therefore, diagnostic accuracies, sensitivities, and specificities were calculated in B-mode US alone, elastography alone, and combined B-mode US with elastography using the cutoff values of the B-mode US and elastographic parameters. All statistical analyses were performed using MedCalc software ver. 12.3.0 (Mariakerke, Belgium). The $P$-values $<0.05$ were considered statistically significant.

Table 1. Comparison of clinicopathologic and radiologic factor for predicting malignancy

\begin{tabular}{|c|c|c|c|}
\hline Variable & Malignant $(n=41)$ & Benign $(n=54)$ & $P$-value \\
\hline Age (yr) & $47.6 \pm 14.5$ & $55.5 \pm 13.9$ & 0.009 \\
\hline Sex & & & 0.240 \\
\hline Male & 13 & 11 & \\
\hline Female & 28 & 43 & \\
\hline Mean US nodule size (mm) & $12.0 \pm 7.3$ & $15.7 \pm 10.2$ & 0.110 \\
\hline \multicolumn{4}{|l|}{ US finding } \\
\hline Composition & & & $<0.001$ \\
\hline Solid & 41 & 29 & \\
\hline Mixed & 0 & 25 & \\
\hline Echogenicity & & & $<0.001$ \\
\hline Marked hypo & 8 & 0 & \\
\hline Hyро & 26 & 10 & \\
\hline Iso & 3 & 20 & \\
\hline Hyper & 4 & 24 & \\
\hline Margin & & & $<0.001$ \\
\hline Irregular/microlobulated & 33 & 11 & \\
\hline Smooth & 8 & 43 & \\
\hline Shape & & & $<0.001$ \\
\hline Taller than wide & 24 & 10 & \\
\hline Wider than tall & 17 & 44 & \\
\hline Calcification & & & $<0.001$ \\
\hline Yes & 30 & 8 & \\
\hline No & 11 & 46 & \\
\hline US category & & & $<0.001$ \\
\hline Low suspicion & 0 & 26 & \\
\hline Intermediate suspicion & 2 & 20 & \\
\hline High suspicion & 39 & 8 & \\
\hline \multicolumn{4}{|l|}{ Elasticity parameter } \\
\hline$E_{\max }(\mathrm{kPa})$ & $67.0 \pm 45.1$ & $51.8 \pm 45.0$ & 0.030 \\
\hline$E_{\text {mean }}(\mathrm{kPa})$ & $52.7 \pm 36.3$ & $38.0 \pm 30.9$ & 0.027 \\
\hline $\mathrm{E}_{\min }(\mathrm{kPa})$ & $32.6 \pm 27.4$ & $22.0 \pm 18.5$ & 0.036 \\
\hline$E_{\text {ratio }}$ & $5.3 \pm 6.9$ & $4.1 \pm 5.1$ & 0.340 \\
\hline
\end{tabular}

Values are presented as mean \pm standard deviation.

US, ultrasound; $E_{\max }$, maximum pixel value for a region of interest (ROI); $\mathrm{E}_{\text {mean, }}$ mean value for a 2-mm diameter $\mathrm{ROI}$ placed in the stiffest region; $E_{\text {min, }}$ minimum pixel value for a $\mathrm{ROI}$, $\mathrm{E}_{\text {ratio, }}$ the ratios of mean stiffness for the lesion-to-normal parenchyma.

\section{RESULTS}

\section{Demographic, clinical, and sonographic characteristics}

The 92 subjects included 23 men (mean age, 56.9 years; age range, 30.0 to 73.0 years) and 69 women (mean age, 51.3 years; age range, 22.0 to 76.0 years). Their characteristics are summarized in Table 1. Fifty-four thyroid nodules were benign and 41 were malignant. The thyroid nodules confirmed to be malignant included 39 papillary thyroid carcinomas, one medullary carcinoma, and one anaplastic carcinoma.

The patients with malignant thyroid nodules were significantly younger than those with benign nodules $(P=0.009)$. The mean size of malignant nodules on US $(12.0 \pm 7.3 \mathrm{~mm})$ was not significantly different from that of benign lesions $(15.7 \pm 10.2 \mathrm{~mm}$; $P=0.120$ ) There was no significant difference according to sex or mean US nodule size between benign and malignant nodules. Suspicious US findings (solid composition, hypoechogenicity, an irregular margin, presence of calcifications, and taller-than-wide shape) and the US category of high suspicion were significantly more frequent in malignant nodules than in benign nodules (all $P<0.001)$. Except $E_{\text {ratio }}$, the mean values of all elasticity parameters were significantly higher in malignant thyroid nodules than in benign nodules $(P<0.05)$ (Table 1$)$.

\section{Predictors of thyroid malignancy}

On multivariate logistic regression analysis, age (OR, 0.90; $P=$ 0.028), a taller-than-wide shape (OR, 11.3; $P=0.040)$, the presence of calcifications (OR, 15.0; $P=0.021)$, and $E_{\max }(\mathrm{OR}, 1.22$; $P=0.021)$ were found to be independent risk factors for malignancy in thyroid nodules (Table 2).

\section{Diagnostic performance of each US feature, US category, and elasticity parameter and optimal cutoff values on SWE for predicting thyroid malignancy}

Hypoechogenicity showed the highest AUC (0.838) of the Bmode US features. Among the quantitative SWE parameters,

Table 2. Multivariate logistic regression analysis of clinical and radiologic factor for predicting malignancy

\begin{tabular}{lcc}
\hline Variable & $\mathrm{OR}(95 \% \mathrm{Cl})$ & $P$-value \\
\hline Age & $0.90(0.82-0.99)$ & 0.028 \\
Composition (reference:mixed) & $0(0-0)$ & 0.990 \\
Echogenicity (reference:hyperechogenicity) & $0(0-0)$ & 0.230 \\
Margin (reference:smooth margin) & $3.0(0.42-21.4)$ & 0.360 \\
Shape (reference:wider than tall) & $11.3(1.23-114.6)$ & 0.040 \\
Calcification (reference:no calcification) & $15.0(1.49-150.2)$ & 0.021 \\
US category (reference:low suspicion) & $0(0-0)$ & 0.280 \\
Emax $_{\text {max }}$ & $1.22(1.2-1.57)$ & 0.021 \\
$E_{\operatorname{mean}}$ & $0.84(0.72-1.01)$ & 0.070 \\
$E_{\min }$ & $1.10(0.98-1.35)$ & 0.058 \\
\hline
\end{tabular}

$\mathrm{OR}$, odds ratio; $\mathrm{Cl}$, confidence interval; $\mathrm{E}_{\max }$, maximum pixel value for a region of interest (ROI); $E_{\text {mean, }}$ mean value for a 2-mm diameter $\mathrm{ROI}$ placed in the stiffest region; $E_{\min }$, minimum pixel value for a $\mathrm{ROI}$. 
Table 3. Diagnostic performance of each B-mode US features and elasticity parameters with optimal cutoff value on SWE for predicting malignancy

\begin{tabular}{llccccc}
\hline Variable & \multicolumn{1}{c}{ Cutoff } & $\begin{array}{c}\text { Sensitivity } \\
(\%)\end{array}$ & $\begin{array}{c}\text { Specificity } \\
(\%)\end{array}$ & PLR & NLR & AUC \\
\hline Composition & Solid & 100 & 46.30 & 1.86 & 0 & 0.731 \\
Echogenicity & Hypoechogenic & 82.93 & 81.48 & 4.48 & 0.21 & 0.838 \\
Margin & Irregular & 80.49 & 79.63 & 3.95 & 0.25 & 0.801 \\
Shape & Taller than wide & 58.54 & 81.48 & 3.16 & 0.51 & 0.700 \\
Calcification & Presence & 73.17 & 85.19 & 4.94 & 0.31 & 0.808 \\
US category & High suspicion & 95.12 & 85.19 & 6.42 & 0.06 & 0.913 \\
$E_{\text {mean }}$ & $>54.9$ & 36.59 & 87.04 & 2.82 & 0.73 & 0.631 \\
$E_{\text {max }}$ & $>47.1$ & 53.66 & 70.37 & 1.81 & 0.66 & 0.633 \\
Emin $_{\text {min }}$ & $>40.4$ & 31.71 & 88.89 & 2.85 & 0.77 & 0.613 \\
ratio $_{\text {r }}$ & $>1.94$ & 92.68 & 29.63 & 1.32 & 0.25 & 0.609 \\
\hline
\end{tabular}

US, ultrasound; SWE, shear wave elastography; PLR, positive likelihood ratio; NLR, negative likelihood ratio; AUC, area under the receiver operating characteristic curve; $E_{\text {mean, }}$ mean value for a 2-mm diameter region of interest $(\mathrm{ROI})$ placed in the stiffest region; $E_{\max }$, maximum pixel value for a

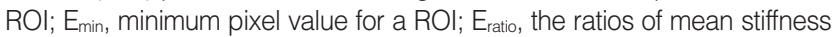
for the lesion-to-normal parenchyma.

$\mathrm{E}_{\max }$ showed a somewhat higher AUC (0.633) than the other elasticity parameters, including $\mathrm{E}_{\text {mean }}, \mathrm{E}_{\min }$, and $\mathrm{E}_{\text {ratio, }}$, with a sensitivity of $53.66 \%$ and a specificity of $70.37 \%$. The optimal threshold values of the elasticity parameters for predicting malignancy in thyroid nodules were as follows: $\mathrm{E}_{\operatorname{mean}}, 54.9 \mathrm{kPa} ; \mathrm{E}_{\max }, 47.1 \mathrm{kPa}$; $\mathrm{E}_{\text {mean, }}, 40.4 \mathrm{kPa}$; and $\mathrm{E}_{\text {ratio }}, 1.94$. The US category of high suspicion showed a sensitivity of $95.1 \%$, a specificity of $85.2 \%$, and an AUC of 0.913, which were all higher than the corresponding values of the SWE parameters (Table 3).

\section{Diagnostic performance of combinations of SWE parameters with B-mode US findings}

Combining the US category of high suspicion with the elasticity parameters generally yielded better diagnostic performance than using only the US category. Combining the US category of high suspicion with $\mathrm{E}_{\max }$ resulted in a higher sensitivity than using the US category alone, as well as a negative predictive value of $100 \%$. Combining the US category of high suspicion with $\mathrm{E}_{\min }$ demonstrated a higher specificity and positive predictive value than using the US category alone $(88.89 \%$ and $86.96 \%$, respectively). A higher accuracy $(92.63 \%)$ resulted from combining the US category with $\mathrm{E}_{\min }$. However, combining the US category of high suspicion with SWE parameters did not yield significant improvements in diagnostic performance compared with the use of the US category alone (Table 4).

\section{DISCUSSION}

Our study revealed that patients with malignant thyroid nodules were significantly younger (mean age, 47.6 years) than those with benign nodules (mean age, 55.5 years). This is consistent
Table 4. Comparison of diagnostic performance of US category and combined US category with SWE parameters

\begin{tabular}{|c|c|c|c|c|c|}
\hline Variable & Sensitivity & Specificity & PPV & NPV & Accuracy \\
\hline US category & $\begin{array}{l}95.12 \\
(39 / 41)\end{array}$ & $\begin{array}{l}85.19 \\
(46 / 54)\end{array}$ & $\begin{array}{l}82.98 \\
(39 / 47)\end{array}$ & $\begin{array}{c}95.83 \\
(46 / 48)\end{array}$ & $\begin{array}{l}89.47 \\
(85 / 95)\end{array}$ \\
\hline $\begin{array}{l}\text { US category+ } E_{\max } \\
\text { (combination) }\end{array}$ & $\begin{array}{c}100 \\
(41 / 41)\end{array}$ & $\begin{array}{l}85.19 \\
(46 / 54)\end{array}$ & $\begin{array}{l}83.67 \\
(41 / 49)\end{array}$ & $\begin{array}{c}100 \\
(46 / 46)\end{array}$ & $\begin{array}{l}91.58 \\
(87 / 95)\end{array}$ \\
\hline $\begin{array}{l}\text { US category+Emean } \\
\text { (combination) }\end{array}$ & $\begin{array}{l}97.56 \\
(40 / 41)\end{array}$ & $\begin{array}{l}87.04 \\
(47 / 54)\end{array}$ & $\begin{array}{l}85.11 \\
(40 / 47)\end{array}$ & $\begin{array}{c}97.92 \\
(47 / 48)\end{array}$ & $\begin{array}{l}91.58 \\
(87 / 95)\end{array}$ \\
\hline \multirow[t]{2}{*}{$\begin{array}{l}\text { US category+ } \mathrm{E}_{\min } \\
\text { (combination) }\end{array}$} & $\begin{array}{l}97.56 \\
(40 / 41)\end{array}$ & $\begin{array}{c}88.89 \\
(48 / 54)\end{array}$ & $\begin{array}{c}86.96 \\
(40 / 46)\end{array}$ & $\begin{array}{c}97.96 \\
(48 / 49)\end{array}$ & $\begin{array}{l}92.63 \\
(88 / 95)\end{array}$ \\
\hline & $P$-value & $P$-value & $P$-value & $P$-value & $P$-value \\
\hline $\begin{array}{l}\text { US category vs. } \\
\text { US category+Emax }\end{array}$ & 0.47 & 1.0 & 0.85 & 0.49 & 0.80 \\
\hline $\begin{array}{l}\text { US category vs. } \\
\text { US category+Emean }\end{array}$ & 1.0 & 0.99 & 0.99 & 0.99 & 0.80 \\
\hline $\begin{array}{l}\text { US category vs. } \\
\text { US category+Emin }\end{array}$ & 1.0 & 0.77 & 0.81 & 0.98 & 0.61 \\
\hline $\begin{array}{l}\text { US category vs. } \\
\text { US category+Eratio }\end{array}$ & 1.0 & 1.0 & 0.82 & 0.99 & 0.99 \\
\hline
\end{tabular}

Values are presented as percent (number).

US, ultrasound; SWE, shear wave elastography; PPV, positive predictive value; NPV, negative predictive value; $E_{\max }$, maximum pixel value for a region of interest (ROI); $E_{\text {mean, }}$ mean value for a 2-mm diameter ROI placed in the stiffest region; $E_{\min }$, minimum pixel value for a $R O I$; $E_{\text {ratio, }}$ the ratios of mean stiffness for the lesion-to-normal parenchyma.

with the results of a previous large-scale study of the use of SWE to detect cancer in thyroid nodules that found the mean age of patients with a thyroid malignancy to be 42.9 years, while the mean age of those with benign nodules was 52.2 years [23]. When assessing indeterminate or suspicious thyroid nodules, a more careful evaluation is required if the patient is relatively young.

We investigated B-mode US finding features that could be useful for differentiating malignant from benign thyroid nodules, and found that solid composition, hypoechogenicity, an irregular/microlobulated margin, a taller-than-wide shape, and the presence of calcifications were significantly more common in malignant thyroid nodules than in benign thyroid nodules. These results are consistent with those of previous studies on US findings suggestive of malignancy in thyroid nodules [24-26]. In the present study, we compared and evaluated the thyroid nodules using SWE. All elasticity parameters except $E_{\text {ratio }}\left(E_{\max }, E_{\text {mean }}\right.$, and $\mathrm{E}_{\min }$ ) on SWE were significantly higher for malignant thyroid nodules than for benign thyroid nodules. This observed relationship between elasticity and the likelihood of thyroid malignancy is consistent with several prior publications analyzing the use of SWE [11,18-21,23].

Among the elasticity parameters, only $\mathrm{E}_{\max }$ was found to be an independent risk factor for malignancy in thyroid nodules in the multivariate logistic regression analysis $(\mathrm{OR}, 1.22 ; 95 \% \mathrm{CI}$, 1.20 to $1.57, P=0.021)$. $\mathrm{E}_{\max }$ had the best diagnostic performance, with a sensitivity, specificity, and AUC of $53.7 \%, 70.4 \%$, and 
0.633 , respectively. In concordance with the present results, Wang et al. [27] also reported, in a study of 322 thyroid nodules, that $\mathrm{E}_{\max }$ was the only independently significant SWE imaging parameter, with a sensitivity of $59.40 \%$, a specificity of $89.8 \%$, and an AUC of 0.796 for differentiating between malignant and benign thyroid nodules.

Several studies have reported a somewhat variable range of values of SWE imaging parameters that could be used to predict thyroid malignancies, especially regarding the optimal cutoff value of $E_{\max }$. In our study, in which $43 \%$ of the nodules were malignant, the optimal cutoff value of $E_{\max }$ was $47.1 \mathrm{kPa}$, while those of $E_{\text {mean }}$ and $E_{\min }$ were $54.9 \mathrm{kPa}$ and $40.4 \mathrm{kPa}$, respectively. A prior study reported similar results to ours, demonstrating that the optimal cutoff value of $\mathrm{E}_{\max }$ was $47.0 \mathrm{kPa}$ for predicting malignancy in 322 nodules, of which 33\% were malignant [27]. However, Liu et al. [21], in an analysis of 313 nodules, of which 194 were malignant, reported that the optimal cutoff value of $\mathrm{E}_{\max }$ was $51.9 \mathrm{kPa}$, with a sensitivity of $81.4 \%$ and a specificity of $83.2 \%$. This may reflect the higher proportion of malignant nodules than in our study, because malignant nodules show higher SWE values than benign nodules. In contrast, Veyrieres et al. [19] analyzed 297 nodules, of which only $12 \%$ were malignant, and reported a high threshold cutoff value of $E_{\max }(66$ $\mathrm{kPa}$ ) with high sensitivity $(80.0 \%)$, specificity $(90.5 \%)$, and negative predictive value $(97.1 \%)$, but with a relatively low positive predictive value $(52.8 \%)$. Thyroid malignancies with a maximum diameter equal to or less than $1 \mathrm{~cm}$ showed significantly lower SWE values than nodules larger than $1 \mathrm{~cm}$, probably because larger nodules might be subjected to higher precompression due to their convex bulging through the skin [28]. While the mean diameter of the thyroid malignancies studied by Veyrieres et al. [19] was $25.0 \pm 13.8 \mathrm{~mm}$, the mean diameter was $15.7 \pm 10.2 \mathrm{~mm}$ in our study. As discussed above, the optimal cutoff values of SWE parameters vary considerably due to differences in the number of enrolled patients, the proportion of malignant thyroid nodules, and nodule size. Furthermore, several other characteristics of nodules, such as the presence of calcifications or cystic changes and their position, could affect the results [28]. Therefore, it is necessary to further assess the optimal cutoff values for predicting malignant thyroid nodules in a general screening population in a future study.

A previous study including 313 thyroid nodules reported that combining B-mode US findings with SWE parameters improved diagnostic performance for detecting thyroid malignancy, with the sensitivity and negative predictive value increasing from $89.7 \%$ and $84.0 \%$ to $94.6 \%$ and $90.0 \%$, respectively [21]. However, the specificity and positive predictive value slightly decreased when B-mode US findings and SWE were combined. Another previous large-scale study involving 476 thyroid nodules showed similar results. The combination of B-mode US findings and elasticity parameters significantly increased the sensitivity, negative predictive value, and AUC from $92.9 \%$,
$68.7 \%$, and 0.769 to $95.0 \%, 74.0 \%$, and 0.834 , respectively, but with slight decreases in the specificity and positive predictive value [18]. In our study, we observed slight improvements in all parameters of diagnostic performance as a result of combining the B-mode US category of high suspicion with each elasticity parameter, compared with using only the B-mode US category. It was especially meaningful that the sensitivity and negative predictive value increased from $95.1 \%$ and $95.8 \%$, respectively, when using only the B-mode US category, to $100 \%$ and $100 \%$, respectively, when combining the B-mode US category with $\mathrm{E}_{\max }$. Screening thyroid US requires a high sensitivity and a high negative predictive value in order to avoid unnecessary biopsies and surgical resections. However, in this present study, no statistically significant added benefit in diagnostic performance was achieved by adding SWE. This may have been due to the excellent diagnostic performance of the B-mode US category of high suspicion by itself, with a sensitivity of $95.1 \%$, a specificity of $85.12 \%$, a positive predictive value of $82.9 \%$, a negative predictive value of $95.8 \%$, and an accuracy of $89.5 \%$.

There were several limitations of this study. First, selection bias was inevitable due to its retrospective design. Second, this study was based on results obtained by two operators, and we did not assess interobserver variability. However, SWE is known to be relatively reproducible and minimally operator-dependent. All thyroid nodule data were obtained using the same protocol to minimize operator bias. Third, this study included a relatively small number of thyroid nodules and only presented experiences from a single center. Therefore, our findings should be verified by a prospective study with a large population. Lastly, there was an unusually high proportion of malignant nodules in our study group. The patients included in the present study who had indeterminate or suspicious lesions underwent US FNA or surgical removal.

SWE is a valuable additional diagnostic tool for accurately stratifying the risk of thyroid nodules in routine clinical settings. A combination of B-mode US with SWE yielded improved diagnostic performance compared to B-mode US findings only, although the differences in diagnostic performance were statistically non-significant.

\section{CONFLICT OF INTEREST}

No potential conflict of interest relevant to this article was reported.

\section{ORCID}

Eung Koo Yeon https://orcid.org/0000-0001-7965-0118

Yu-Mee Sohn https://orcid.org/0000-0002-2238-0724

Mirinae Seo https://orcid.org/0000-0002-8989-9504 
Eui-Jong Kim https://orcid.org/0000-0003-2183-8657

Young-Gyu Eun https://orcid.org/0000-0003-4081-5207

Won Seo Park https://orcid.org/0000-0002-7012-5218

Seong Jong Yun https://orcid.org/0000-0002-3775-5701

\section{AUTHOR CONTRIBUTIONS}

Conceptualization: YMS. Data curation: YMS, EKY. Formal analysis: SJY. Methodology: YMS, MS. Project administration: YMS. Visualization: EKY. Writing - original draft: EKY. Writing - review \& editing: YMS, EJK, YGE,WSP.

\section{REFERENCES}

1. Kim EK, Park CS, Chung WY, Oh KK, Kim DI, Lee JT, et al. New sonographic criteria for recommending fine-needle aspiration biopsy of nonpalpable solid nodules of the thyroid. AJR Am J Roentgenol. 2002 Mar;178(3):687-91.

2. Ha EJ, MoonWJ, Na DG, LeeYH, Choi N, Kim SJ, et al.A multicenter prospective validation study for the Korean thyroid imaging reporting and data system in patients with thyroid nodules. Korean J Radiol. 2016 Sep-Oct;17(5):811-21.

3. Hoang JK, LeeWK, Lee M, Johnson D, Farrell S. US Features of thyroid malignancy: pearls and pitfalls. Radiographics. 2007 May-Jun; 27(3):847-60.

4. Iannuccilli JD, Cronan JJ, Monchik JM. Risk for malignancy of thyroid nodules as assessed by sonographic criteria: the need for biopsy. J Ultrasound Med. 2004 Nov;23(11):1455-64.

5. Alexander EK. Approach to the patient with a cytologically indeterminate thyroid nodule. J Clin Endocrinol Metab. 2008 Nov;93(11): 4175-82.

6. Castro MR, Gharib H. Thyroid fine-needle aspiration biopsy: progress, practice, and pitfalls. Endocr Pract. 2003 Mar-Apr;9(2):128-36.

7. Cosgrove D, Barr R, Bojunga J, CantisaniV, Chammas MC, Dighe M, et al. WFUMB guidelines and recommendations on the clinical use of ultrasound elastography. Part 4: thyroid. Ultrasound Med Biol. 2017 Jan;43(1):4-26.

8. Ophir J, Cespedes I, Ponnekanti H, Yazdi Y, Li X. Elastography: a quantitative method for imaging the elasticity of biological tissues. Ultrason Imaging. 1991 Apr;13(2):111-34.

9. Nell S, Kist JW, Debray TP, de Keizer B, van Oostenbrugge TJ, Borel Rinkes IH, et al. Qualitative elastography can replace thyroid nodule fine-needle aspiration in patients with soft thyroid nodules: a systematic review and meta-analysis. Eur J Radiol. 2015 Apr;84(4): 652-61.

10. Asteria C, Giovanardi A, Pizzocaro A, Cozzaglio L, Morabito A, Somalvico $\mathrm{F}$, et al. US-elastography in the differential diagnosis of benign and malignant thyroid nodules. Thyroid. 2008 May;18(5):52331.

11. Monpeyssen H,Tramalloni J, Poiree S, Helenon O, Correas JM. Elastography of the thyroid. Diagn Interv Imaging. 2013 May;94(5):53544.

12. Tanter M, Bercoff J,Athanasiou A, DeffieuxT, Gennisson J, Montaldo $\mathrm{G}$, et al. Quantitative assessment of breast lesion viscoelasticity: initial clinical results using supersonic shear imaging. Ultrasound Med Biol. 2008 Sep;34(9):1373-86.

13. Athanasiou A, Tardivon A, Tanter M, Sigal-Zafrani B, Bercoff J, Def- fieux T, et al. Breast lesions: quantitative elastography with supersonic shear imaging--preliminary results. Radiology. 2010 Jul;256(1): 297-303.

14. Liu BX, Xie XY, Liang JY, Zheng YL, Huang GL, Zhou LY, et al. Shear wave elastography versus real-time elastography on evaluation thyroid nodules: a preliminary study. Eur J Radiol. 2014 Jul;83(7):1135-43.

15. Cantisani V, D’AndreaV, Biancari F, Medvedyeva O, Di Segni M, Olive $\mathrm{M}$, et al. Prospective evaluation of multiparametric ultrasound and quantitative elastosonography in the differential diagnosis of benign and malignant thyroid nodules: preliminary experience. Eur J Radiol. 2012 Oct;81(10):2678-83.

16. Shuzhen C. Comparison analysis between conventional ultrasonography and ultrasound elastography of thyroid nodules. Eur J Radiol. 2012 Aug;81(8):1806-11.

17. Colakoglu B, Yildirim D, Alis D, Ucar G, Samanci C, Ustabasioglu FE, et al. Elastography in distinguishing benign from malignant thyroid nodules. J Clin Imaging Sci. 2016 Dec;6:51.

18. Park AY, Son EJ, Han K, Youk JH, Kim JA, Park CS. Shear wave elastography of thyroid nodules for the prediction of malignancy in a large scale study. Eur J Radiol. 2015 Mar;84(3):407-12.

19. Veyrieres JB,Albarel F, Lombard JV, Berbis J, Sebag F, Oliver C, et al. A threshold value in Shear Wave elastography to rule out malignant thyroid nodules: a reality? Eur J Radiol. 2012 Dec;81(12):3965-72.

20. Chen M, Zhang KQ, Xu YF, Zhang SM, Cao Y, Sun WQ. Shear wave elastography and contrast-enhanced ultrasonography in the diagnosis of thyroid malignant nodules. Mol Clin Oncol. 2016 Dec;5(6): 724-30.

21. Liu Z, Jing H, Han X, Shao H, Sun YX, Wang QC, et al. Shear wave elastography combined with the thyroid imaging reporting and data system for malignancy risk stratification in thyroid nodules. Oncotarget. 2017 Jun;8(26):43406-16.

22. Haugen BR, Alexander EK, Bible KC, Doherty GM, Mandel SJ, Nikiforov YE, et al. 2015 American Thyroid Association management guidelines for adult patients with thyroid nodules and differentiated thyroid cancer: the American Thyroid Association guidelines task force on thyroid nodules and differentiated thyroid cancer. Thyroid. 2016 Jan;26(1):1-133.

23. Azizi G, Keller JM, Mayo ML, Piper K, Puett D, Earp KM, et al.Thyroid nodules and shear wave elastography: a new tool in thyroid cancer detection. Ultrasound Med Biol. 2015 Nov;41(11):2855-65.

24. Kwak JY, Han KH, Yoon JH, Moon HJ, Son EJ, Park SH, et al. Thyroid imaging reporting and data system for US features of nodules: a step in establishing better stratification of cancer risk. Radiology. 2011 Sep;260(3):892-9.

25. Na DG, Baek JH, Sung JY, Kim JH, Kim JK, Choi YJ, et al. Thyroid imaging reporting and data system risk stratification of thyroid nodules: categorization based on solidity and echogenicity.Thyroid. 2016 Apr;26(4):562-72.

26. Shin JH, Baek JH, Chung J, Ha EJ, Kim JH, Lee YH, et al. Ultrasonography diagnosis and imaging-based management of thyroid nodules: revised Korean Society of Thyroid Radiology consensus statement and recommendations. Korean J Radiol. 2016 May-Jun;17(3): 370-95.

27. Wang D, He YP, Zhang YF, Liu BJ, Zhao CK, Fu HJ, et al. The diagnostic performance of shear wave speed (SWS) imaging for thyroid nodules with elasticity modulus and SWS measurement. Oncotarget. 2017 Feb;8(8):13387-99.

28. Bhatia KS,Tong CS, Cho CC, Yuen EH, Lee YY, Ahuja AT. Shear wave elastography of thyroid nodules in routine clinical practice: preliminary observations and utility for detecting malignancy. Eur Radiol. 2012 Nov;22(11):2397-406. 